\title{
Cantharidin induces apoptosis in human bladder cancer TSGH 8301 cells through mitochondria-dependent signal pathways
}

\author{
JEHN-HWA KUO ${ }^{1,2}$, YUNG-LIN CHU ${ }^{3}$, JAI-SING YANG ${ }^{4}$, JING-PIN LIN ${ }^{5}$, KUANG-CHI LAI $^{6,7}$, \\ HSIU-MAAN KUO ${ }^{8}$, TE-CHUN HSIA ${ }^{9}$ and JING-GUNG CHUNG ${ }^{10,11}$
}

\author{
${ }^{1}$ Special Class of Healthcare, Industry Management, Central Taiwan University of Science and Technology, Taichung; \\ ${ }^{2}$ Department of Urology, Jen-Ai Hospital, Tali, Taichung 412; Departments of ${ }^{3}$ Nutrition, ${ }^{4}$ Pharmacology, \\ ${ }^{8}$ Parasitology and ${ }^{10}$ Biological Science and Technology; Schools of ${ }^{5}$ Chinese Medicine and ${ }^{6}$ Medicine, \\ China Medical University ; ${ }^{9}$ Department of Internal Medicine, China Medical University Hospital, Taichung 404; \\ ${ }^{7}$ Department of Surgery, China Medical University Beigang Hospital, Yunlin $651 ;{ }^{11}$ Department of Biotechnology, \\ Asia University, Wufeng, Taichung 413, Taiwan, R.O.C.
}

Received May 31, 2010; Accepted July 16, 2010

DOI: 10.3892/ijo_00000775

\begin{abstract}
Cantharidin has shown potent anticancer activities on many types of human cancer cells. This study was performed to elucidate whether mitochondria and caspases are involved in the modulation of apoptosis and cell cycle arrest by cantharidin in human bladder cancer cells. The effect of cantharidin on cell cycle arrest, apoptosis, caspases, reactive oxygen species (ROS) and mitochondrial membrane potential $\left(\Delta \Psi_{m}\right)$ were measured by flow cytometry, and the levels of apoptosis-associated proteins and its regulatory molecules were studied by Western blotting. Cantharidininduced apoptosis and DNA damage was determined by flow cytometric analysis, DAPI staining and Comet assay. After cantharidin treatment, the active forms of caspase-3, -8 and -9 were promoted. Cantharidin-induced apoptosis was associated with enhanced ROS and $\mathrm{Ca}^{2+}$ generations, caused DNA damage, decreased the levels of $\Delta \Psi_{m}$ and promoted Endo G and AIF released from mitochondria. Cantharidininduced G0/G1 arrest was associated with a marked decrease in the protein expressions of cyclin $\mathrm{E}$ and $\mathrm{Cdc} 25 \mathrm{c}$ but promoted the levels of p21 and p-p53. Cantharidin-induced apoptosis was accompanied with up-regulation of the protein expression of Bax and PARP, but down-regulation of the protein levels of Bcl-2, resulting in dysfunction of mitochondria then led to Endo G and AIF release for causing induction of apoptosis.
\end{abstract}

Correspondence to: Dr Jing-Gung Chung, Department of Biological Science and Technology, China Medical University, No. 91, Hsueh-Shih Road, Taichung 404, Taiwan, R.O.C.

E-mail: jgchung@mail.cmu.edu.tw

Key words: cantharidin, human bladder cancer TSGH 8301 cells, apoptosis, mitochondria

\section{Introduction}

Bladder cancer is one of the leading causes of death in the world. Based on the 2008 report from the Department of Health, R.O.C. (Taiwan) indicated that 3.0 individuals per 100,000 die annually from bladder cancer in Taiwan. The current treatment modalities are inadequate. Therefore, novel therapies are needed to reduce the effects of the increasing incidence of bladder cancer. Numerous studies have been shown that cytotoxic agents and DNA damaging agents can induce cell cycle arrest and induce apoptotic cell death (1-3).

Apoptosis is a highly regulated mechanism leading cells to undergo programmed cell death through the extrinsic and the intrinsic pathways $(4,5)$. The extrinsic pathway is triggered by the interaction between specific ligands and surface receptors (6) of cells such as CD95/Fas, tumor necrosis factor (TNF) and death receptors (5). The intrinsic pathway is triggered by various stimuli such as DNA damage, cellular distress, hypoxia and cytotoxic agents, which act inside the cell (5). The third apoptotic pathway is called endoplasmic reticulum (ER) stress pathway (7) which is triggered by the interaction between the mitochondria and ER which plays an essential role in ER stress-mediated cell death. Recently, it was reported that apoptosis can be divided into caspasedependent and -independent pathways. The caspase activations are often regulated by various cellular proteins, in particular, the members of the inhibitor of apoptosis such as IAP $(8)$ or Bcl-2 families $(9,10)$. Currently, the cure for bladder cancer including surgery, radiotherapy and chemotherapeutic options, however, they are still inadequate, many studies are focused on identifying new agents and novel targets for treating bladder cancer. To induce apoptosis of cancer cells is one of the best strategies for treatment of cancer by chemotherapeutic agents.

Cantharidin, a type of terpenoid, is a derivative of Blister Beetles belonging to the order of Coleoptera and the family of Meloidae (11), and it is used in Chinese medicine (12). Cantharidin was reported to induce cell cycle arrest (13) and apoptosis in many human cancer cells such as hepatoma 
(14), colon cancer (15), bladder carcinoma (16), breast cancer (17) and oral buccal carcinoma and leukemia cells (18). Also it was reported that cantharidin induced cell cycle arrest in the $\mathrm{G} 2 / \mathrm{M}$ phase and induced apoptosis in human bladder cancer T24 cells. In addition, cantharidin also stimulated COX2 over-expression and PGE2 production in T24 cells, in a dose-dependent manner (16). However, there is no available information to address the effects of the cantharidin on human bladder carcinoma TSGH 8301 cells. Therefore, in this study, we selected human bladder carcinoma TSGH 8301 cells for examining the effects of cantharidin on cell cycle arrest and apoptosis and results showed that cantharidin potently induced cell cycle arrest and apoptosis in TSGH 8301 cells. The results showed that cantharidin induced $\mathrm{G} 2 / \mathrm{M}$ arrest and apoptosis which is mitochondrial-dependent and via JNK signal pathways offering new information to show cantharidininduced apoptosis in bladder carcinoma TSGH 8301 cells.

\section{Materials and methods}

Chemicals and reagents. Cantharidin, dimethyl sulfoxide (DMSO), potassium phosphates, propidium iodide (PI), ribonuclease-A, Tris-HCl, Triton X-100 and trypan blue were purchased from Sigma Chemical Co. (St. Louis, MO, USA). RPMI-1640 medium with $2 \mathrm{mM}$ L-glutamine $+10 \%$ fetal bovine serum, penicillin-streptomycin and trypsin-EDTA were obtained from Gibco BRL (Grand Island, NY, USA).

Cell culture. The human bladder carcinoma TSGH 8301 cell line were obtained from the Food Industry Research and Development Institute (Hsinchu, Taiwan). TSGH 8301 cells were cultured on $75 \mathrm{~cm}^{2}$ tissue culture flasks with RPMI1640 medium (Gibco BRL). The cell medium with $2 \mathrm{mM}$ L-glutamine was adjusted to contain $10 \%$ fetal bovine serum (Gibco BRL), and $1 \%$ penicillin-streptomycin $(100 \mathrm{U} / \mathrm{ml}$ penicillin and $100 \mu \mathrm{g} / \mathrm{ml}$ streptomycin) (19) and grown at $37^{\circ} \mathrm{C}$ under a humidified $5 \% \mathrm{CO}_{2}$ atmosphere.

Determination of cell morphology, viability, cell cycle and apoptosis. TSGH 8301 cells were seeded at a concentration of $5 \times 10^{5}$ cells/well in a 12 -well plate for $24 \mathrm{~h}$, then were incubated with $0,5,10,15,20$ and $25 \mu \mathrm{M}$ of cantharidin at $37^{\circ} \mathrm{C}, 5 \% \mathrm{CO}_{2}$ and $95 \%$ air for $24 \mathrm{~h}$. Cells were examined and photographed by phase-contrast microscope for the examination of morphological changes. Then cells were harvested by centrifugation and were stained with PI $(5 \mu \mathrm{g} / \mathrm{ml})$ then analyzed by flow cytometry (Becton-Dickinson, San Jose, CA, USA) for viability measurements as previously described (19-23). For cell cycle distribution and sub-G1 determination, isolated cells were fixed gently by $70 \%$ ethanol at $4^{\circ} \mathrm{C}$ overnight and then re-suspended in PBS containing $40 \mu \mathrm{g} / \mathrm{ml} \mathrm{PI}$ and $0.1 \mathrm{mg} / \mathrm{ml}$ RNase and $0.1 \%$ Triton X-100 in dark room for $30 \mathrm{~min}$ at $37^{\circ} \mathrm{C}$, then were analyzed with a flow cytometer equipped with an argon ion laser at $488 \mathrm{~nm}$ wavelength (19-23).

DAPI staining. For DAPI staining, approximately $5 \times 10^{4}$ cells $/ \mathrm{ml}$ of TSGH 8301 cells were treated with $0,2.5,5,10$ and $15 \mu \mathrm{M}$ of cantharidin for $24 \mathrm{~h}$. Cells were stained with
DAPI (4,6-diamidino-2-phenylindole dihydrochloride), then examined and photographed using a fluorescence microscope as previously described (19-23).

Detections of ROS (reactive oxygen species), $\mathrm{Ca}^{2+}$ and mitochondrial membrane potential $\left(\Delta \Psi_{m}\right)$. Approximately $2 \times 10^{5}$ cells $/ \mathrm{ml}$ of TSGH 8301 cells were treated with $10 \mu \mathrm{M}$ of cantharidin for $0.5,1,3,6$ and $12 \mathrm{~h}$ then cells from each treatment were harvested and re-suspended in $500 \mu 1$ of 2,7dichlorodihydrofluorescein diacetate (DCFH-DA) $(10 \mu \mathrm{M})$ for ROS, in $500 \mu \mathrm{l}$ of 1-[2-amino-5-(6-carboxyindol-2-yl) phenoxy]-2-(2'-amino-5' methylphenoxy)ethane- $N, N, N^{\prime}, N^{\prime}-$ tetra acetic acid pentaacetoxymethyl ester (Indo 1/AM) (3 $\mu \mathrm{g} / \mathrm{ml})$ for $\mathrm{Ca}^{2+}$ and in $500 \mu \mathrm{l}$ of $\mathrm{DiOC}_{6}(4 \mu \mathrm{mol} / \mathrm{l})$ for $\Delta \Psi_{m}$. Cells was incubated at $37^{\circ} \mathrm{C}$ for $30 \mathrm{~min}$ before being analyzed by flow cytometry (19-23).

Western blotting of cell cycle and apoptosis-associated proteins. Approximately $1 \times 10^{7}$ cells of TSGH 8301 cells were treated with $10 \mu \mathrm{M}$ cantharidin for $0,6,12,24$ and $48 \mathrm{~h}$. Cells were harvested and lysed with lysis buffer containing $40 \mathrm{mM}$ Tris- $\mathrm{HCl}$ (pH 7.4), $10 \mathrm{mM}$ EDTA, $120 \mathrm{mM} \mathrm{NaCl}$, $1 \mathrm{mM}$ dithiothreitol, $0.1 \%$ nonide P-40 and the total proteins were quantitated as described previously (19-23) and the total proteins $(30 \mu \mathrm{g})$ were used for Western blot analysis and all samples were performed using $10 \%$ Tris-glycineSDS-polyacrylamide gels for $30 \mathrm{~min}$ then the proteins were transferred to a nitrocellulose membrane by electroblotting. Then they were incubated with primary antibodies such as (A) cyclin E, Cdc25c, p21 and p-p53 (Santa Cruz Biotechnology, CA); (B) Bal-2, Bax, caspase-9, AIF, Endo G, caspase-3, PARP and caspase-8 (R\&D Systems, Minneapolis, USA), washed and incubated with secondary antibody for enhanced chemiluminescence (NEN Life Science Products, Inc., Boston, MA, USA) as described previously (19-23). As a loading control, we used anti- $\beta$-tubulin (a mouse monoclonal antibody).

Confocal laser scanning microscopy for protein translocation. TSGH 8301 cells at density of $5 \times 10^{4}$ cells/well were cultured on 4-well chamber slides then were treated without or with $5 \mu \mathrm{M}$ catharidin for $24 \mathrm{~h}$. Then cells on the slides were fixed in $4 \%$ formaldehyde in PBS for $15 \mathrm{~min}$, permeabilized with $0.3 \%$ Triton-X 100 in PBS for $1 \mathrm{~h}$ with blocking of non-specific binding sites using 2\% BSA as described previously (24). Primary antibodies to AIF and Endo G (1:100 dilution) (green fluorescence) were used to stain the fixed cells for overnight then were washed twice with PBS and were stained with secondary antibody (FITCconjugated goat anti-mouse IgG at 1:100 dilution), and followed by DNA staining with mitotracker (red fluorescence) as described previously (24). All samples were photomicrographed and were obtained using a Leica TCS SP2 confocal spectral microscope (24).

Statistical analysis. The results are rported as mean \pm SD and the difference between the cantharidin-treated and control groups were analyzed by Student's t-test, a probability of $\mathrm{p}<0.05$ being considered significant. 
A
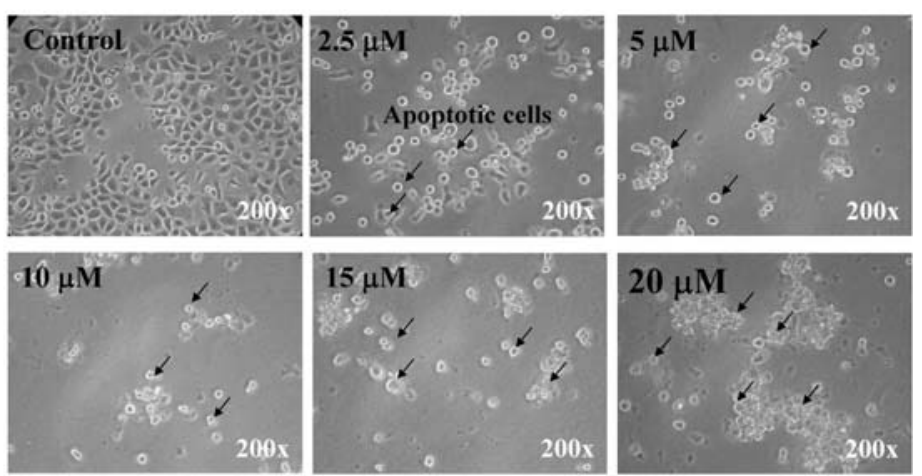

B

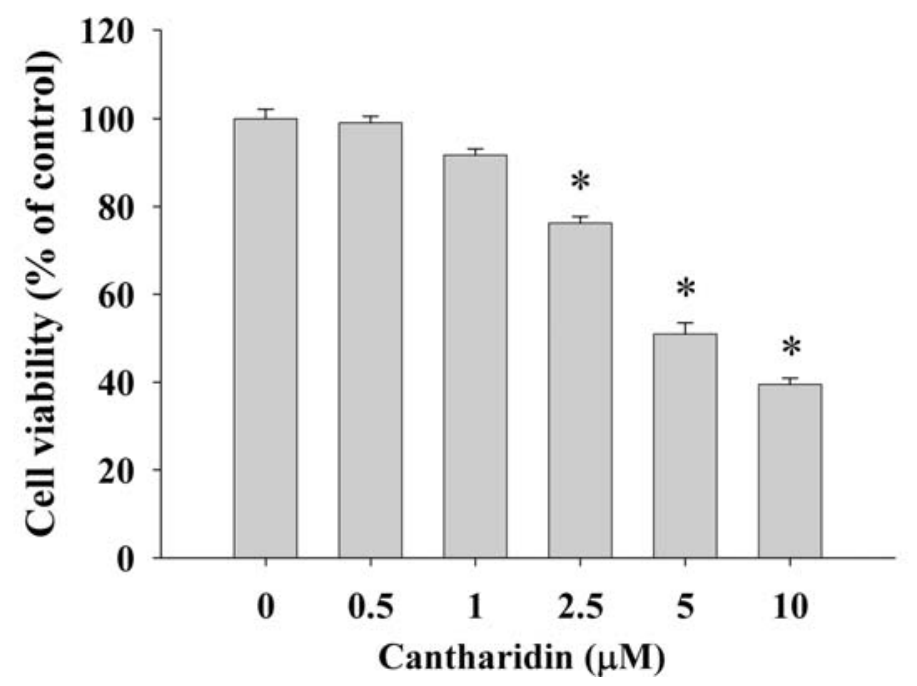

Figure 1. Cantharidin affects the morphology and viability of human bladder cancer TSGH 8301 cells. Cells were treated with different doses of cantharidin for $24 \mathrm{~h}$, then cells were examined and photographed for morphological changes (A) by phase-contrast microscope. Cells were harvested for determination of percentage of viable cells (B) by using flow cytometeric assay as described in Materials and methods. Significantly different from the $0 \mathrm{~h}$ treatment (control) at ${ }^{*} \mathrm{p}<0.05$.

\section{Results}

Effects of cantharidin on TSGH 8301 cell morphology, viability and cell cycle detected by flow cytometry. We determined growth inhibition effects of cantharidin on the morphological changes under phase-contrast microscope, viability and cell cycle distribution by using flow cytometric assay, and the results are shown in Figs. 1A and B, and 2A and B. Increasing the dose of cantharidin and/or time of incubation led to the increase of morphological changes (Fig. 1A) and the decrease of the percentage of viability (Fig. 1B). Cantharidin at $5 \mu \mathrm{M}$ decreased by almost $45 \%$ the viable cells at $48 \mathrm{~h}$ treatment. Fig. 2A and B show that TSGH 8301 cells were exposed to various doses of cantharidin for $24 \mathrm{~h}$ incubation increasing the percentage of cells in G0/G1 dosedependently. The sub-G1 groups (apoptosis) also appeared in the cell cycle distribution.

Effects of cantharidin on DNA damage and apoptosis in TSGH 8301 cells. To investigate cantharidin-induced apoptosis via DNA damage, the TSGH 8301 cells were treated with cantharidin, cells were isolated for DAPI staining and/or cells were stained with Annexin V for apoptosis determination. The results are presented in Fig. 3A and B, which indicate that cantharidin induced DNA condensation and decreased the cell number (Fig. 3A) and induced apoptosis (Fig. 3B), and those effects are dose-dependent.

Effects of cantharidin on the levels of reactive oxygen species (ROS), $\mathrm{Ca}^{2+}$ and mitochondrial membrane potential $\left(\Delta \Psi_{m}\right)$ in TSGH 8301 cells. For investigating whether cantharidininduced apoptosis is via the mitochondrial pathway, TSGH 8301 cells were treated with $5 \mu \mathrm{M}$ cantharidin for various time periods, the levels in ROS and $\mathrm{Ca}^{2+}$ productions and $\Delta \Psi_{m}$ were measured and determined by flow cytometric assay and the results are shown in Fig. 4A-C. These results indicate that cantharidin treatment in TSGH 8301 cells led to an increase in the productions of ROS (Fig. 4A) and $\mathrm{Ca}^{2+}$ (Fig. 4B) and it also induced a decrease of $\Delta \Psi_{m}$ (Fig. 4C). These effects are time-dependent.

Effects of cantharidin on the apoptotic-associated protein translocation in TSGH 8301 cells. For investigating whether cantharidin affected the apoptotic-associated protein translocation in TSGH 8301 cells, the cells $\left(5 \times 10^{4}\right.$ cells/well $)$ were plated on 4-well chamber slides, treated with $5 \mu \mathrm{M}$ 

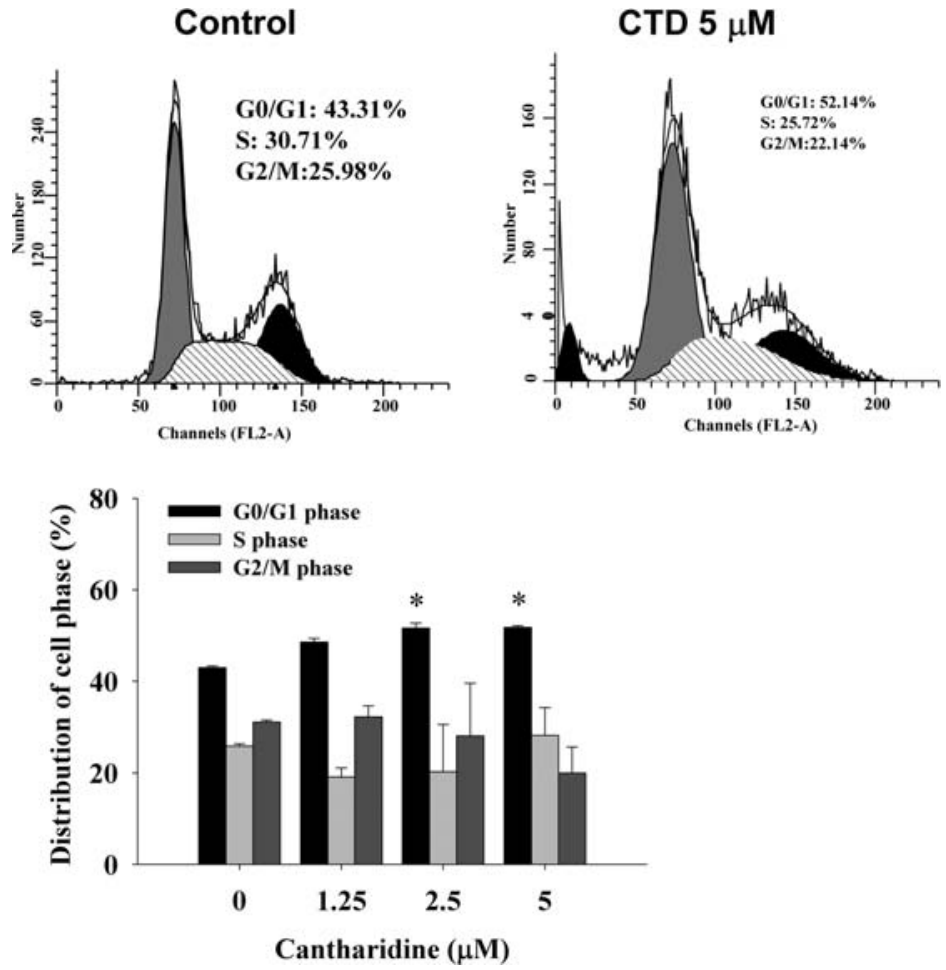

Figure 2. Cantharidin induces cell cycle arrest in TSGH 8301 cells. Cells were treated with $0,2.5,5$ and $10 \mu \mathrm{M}$ of cantharidin for $24 \mathrm{~h}$ then cells were harvested for examinations of cell cycle distribution by flow cytometry as described in Materials and methods. (A) Representative profiles; (B) percentage of cell distribution. Significantly different from the $0 \mathrm{~h}$ treatment (control group) at ${ }^{*} \mathrm{p}<0.05$.

A
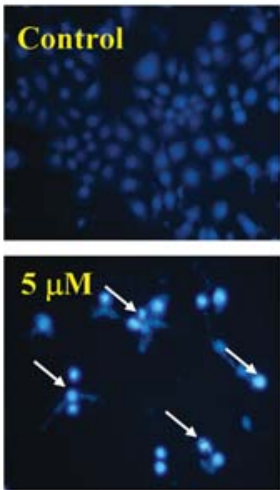

C

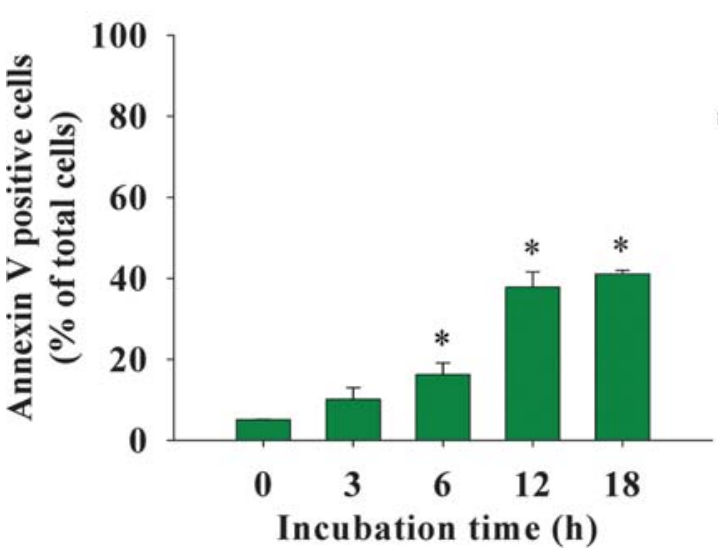

B
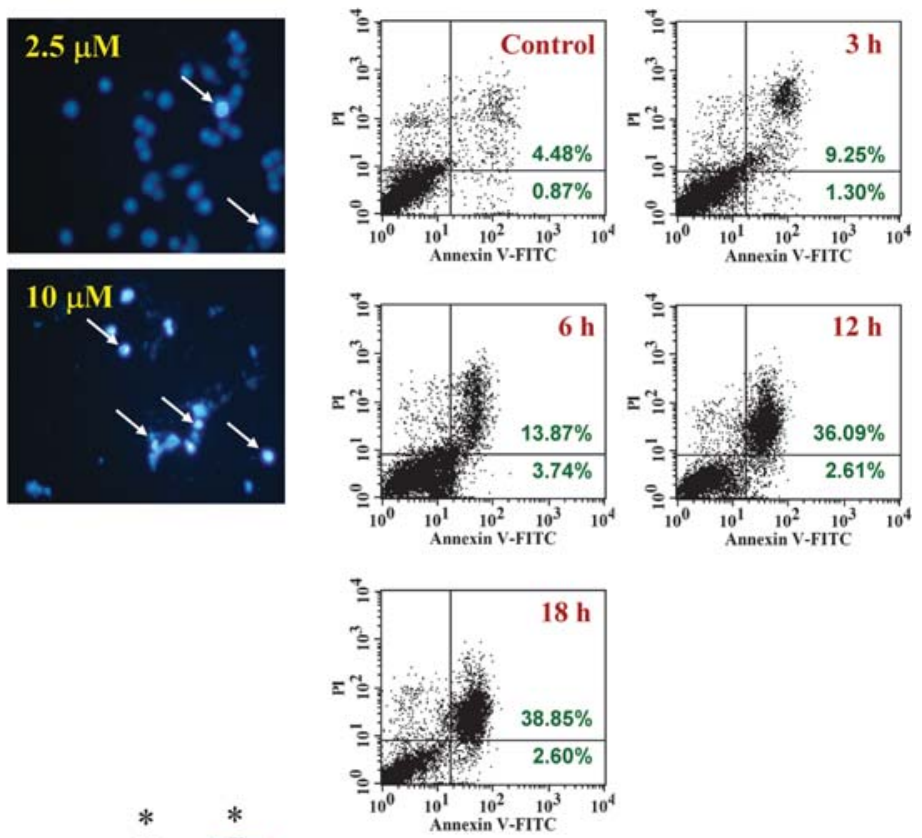

Figure 3. Cantharidin induces DNA damage and apoptosis in TSGH 8301 cells. Cells were treated with $0,1.25,2.5$ and $5 \mu \mathrm{M}$ of cantharidin for 24 h or with $5 \mu \mathrm{M}$ of cantharidin for $0,3,6,12$ and $18 \mathrm{~h}$, then cells were harvested for examinations of DNA damage by DAPI staining (A) or apoptosis by Annexin V staining and were analyzed by flow cytometry (B) as described in Materials and methods. The percentage of apoptosis was calculated (C). Significantly different from the $0 \mathrm{~h}$ treatment (control group) at ${ }^{*} \mathrm{p}<0.05$. 
A
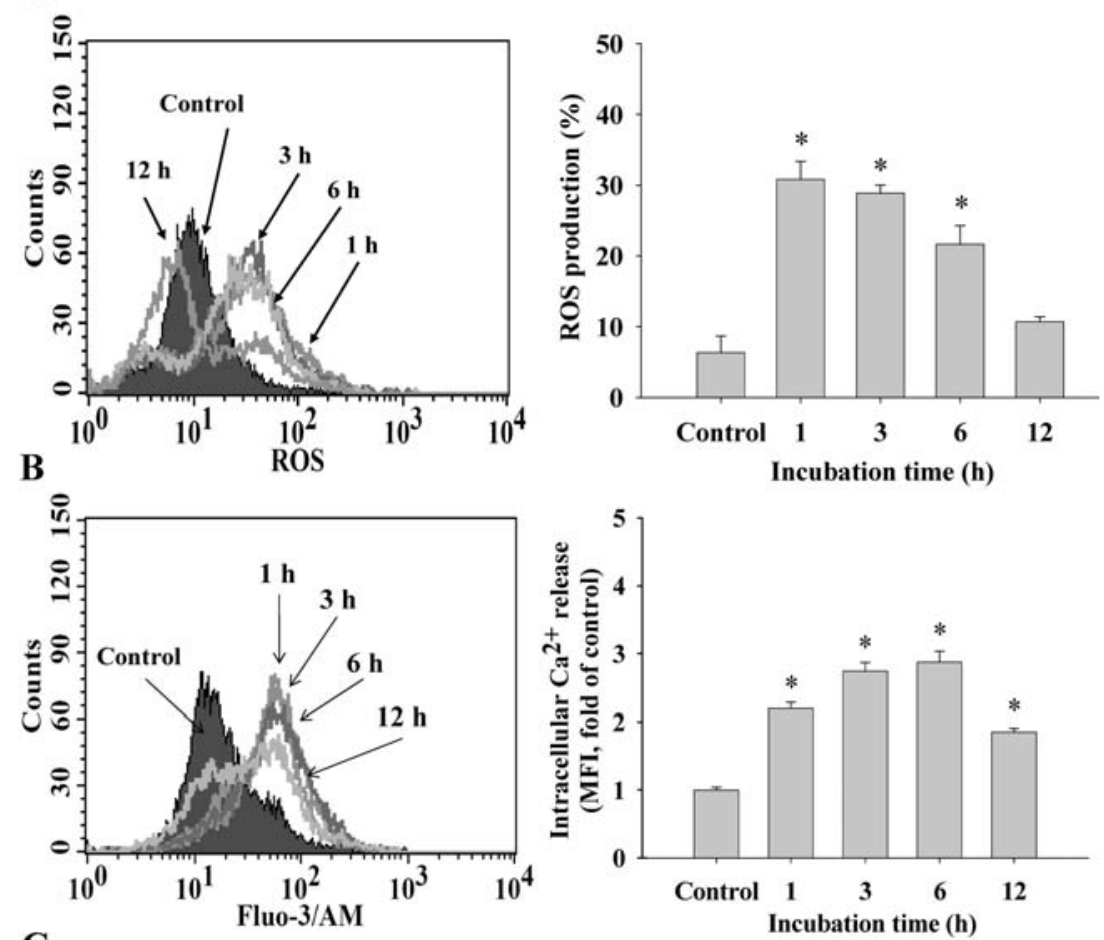

C
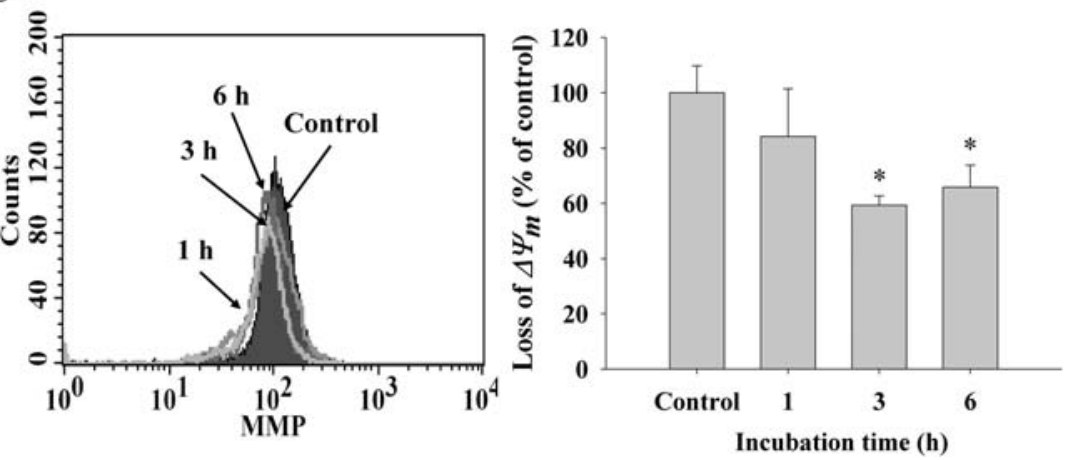

Figure 4. Cantharidin induced reactive oxygen species (ROS) and $\mathrm{Ca}^{2+}$ productions, and affected the levels of mitochondrial membrane potential $\left(\Delta \Psi_{m}\right)$ in TSGH 8301 cells. TSGH 8301 cells $\left(5 \times 10^{5}\right.$ cells $\left./ \mathrm{ml}\right)$ were treated with $5 \mu \mathrm{M}$ of cantharidin for different time periods. Cells were harvested for the percentage of $\operatorname{ROS}(\mathrm{A}), \mathrm{Ca}^{2+}(\mathrm{C})$ and $\Delta \Psi_{m}(\mathrm{~B})$ that were stained by DCFH-DA, DiOC 6 and Indo-1/AM, respectively. The stained cells were determined by flow cytometry as described in the Materials and methods. Values are means \pm SD $(n=3)$. Significantly different from the $0 \mathrm{~h}$ treatment (control group) at ${ }^{*} \mathrm{p}<0.05$.

cantharidin for $24 \mathrm{~h}$, stained by antibody, then examined and photographed by confocal laser microscopic systems. The results are shown in Fig. 5A and B, which indicate that Endo G (Fig. 5A) and AIF (Fig. 5B) are released from mitochondria then translocated to the nuclei. From the double- immunofluorescence labeling it was clearly confirmed by means of confocal scanning microscopy that Endo $\mathrm{G}$ and AIF were increased after exposed to cantharidin in TSGH 8301 cells.

The effects of cantharidin on the associated protein levels of apoptosis in TSGH 8301 cells. For investigating cantharidininduced apoptosis through the possible signaling pathways in TSGH 8301 cells, cells were treated with $10 \mu \mathrm{M}$ of cantharidin for various time periods then protein levels were analyzed by Western blotting. The results are shown in Fig. 6, where cantharidin increased p21 and p-p53 but decreased the levels of cyclin $\mathrm{E}$ and $\mathrm{Cdc} 25 \mathrm{c}$ that led to $\mathrm{G} 0 / \mathrm{G} 1$ phase arrest
(Fig. 6A), however, cantharidin increased the levels of Bax, cleavage-caspase-8, -9, -3, AIF Endo G and PARP (Fig. 6B) protein levels but decreased cytosolic Bcl-2 (Fig. 6B) protein levels in TSGH 8301 cells, leading to apoptosis. We suggest that cantharidin-induced apoptosis is mediated by the mitochondrial and ER stress pathways.

\section{Discussion}

Natural products and their derivatives such as instance, vinca alkaloids, taxanes and camptothecins, have been used commonly in cancer chemotherapy (25), however, the majority of natural products come from plants, but animal studies are few. Substantial evidence has shown that cantharidin induced cell cycle arrest and apoptosis in many human cancer cell lines including human bladder T24 cancer cells. In particular, cantharidin induced apoptosis via active caspase-3 in T24 cells (16). In the present study, we used the human bladder 
A
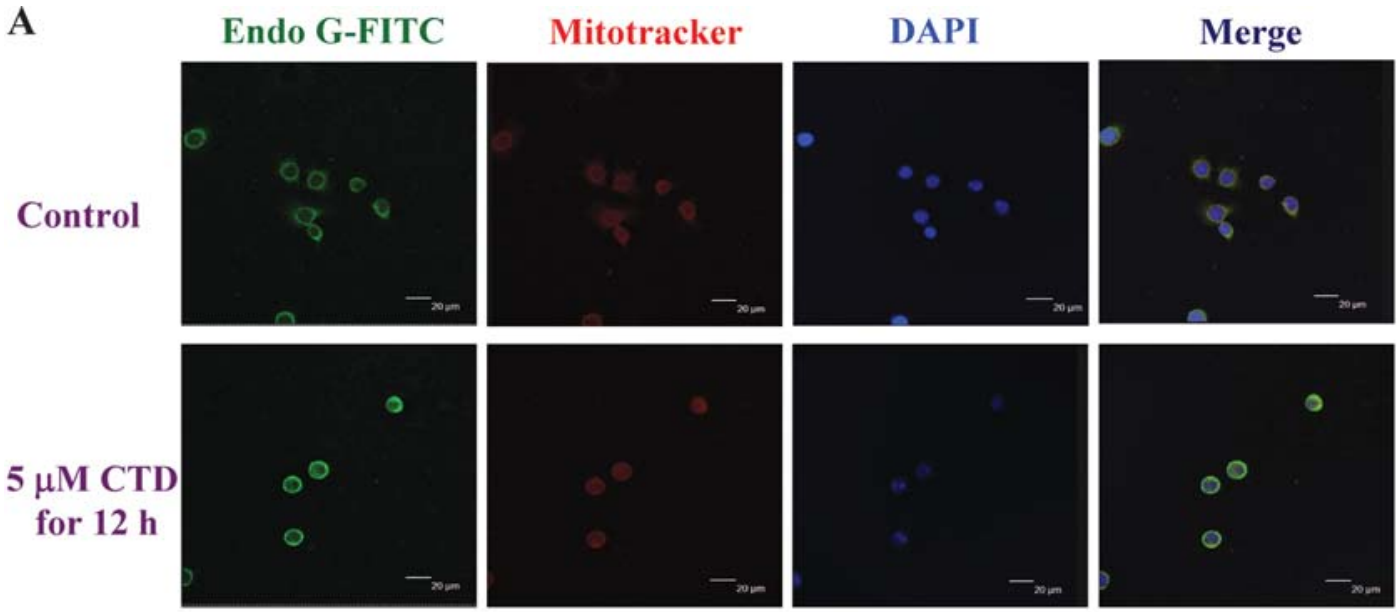

B

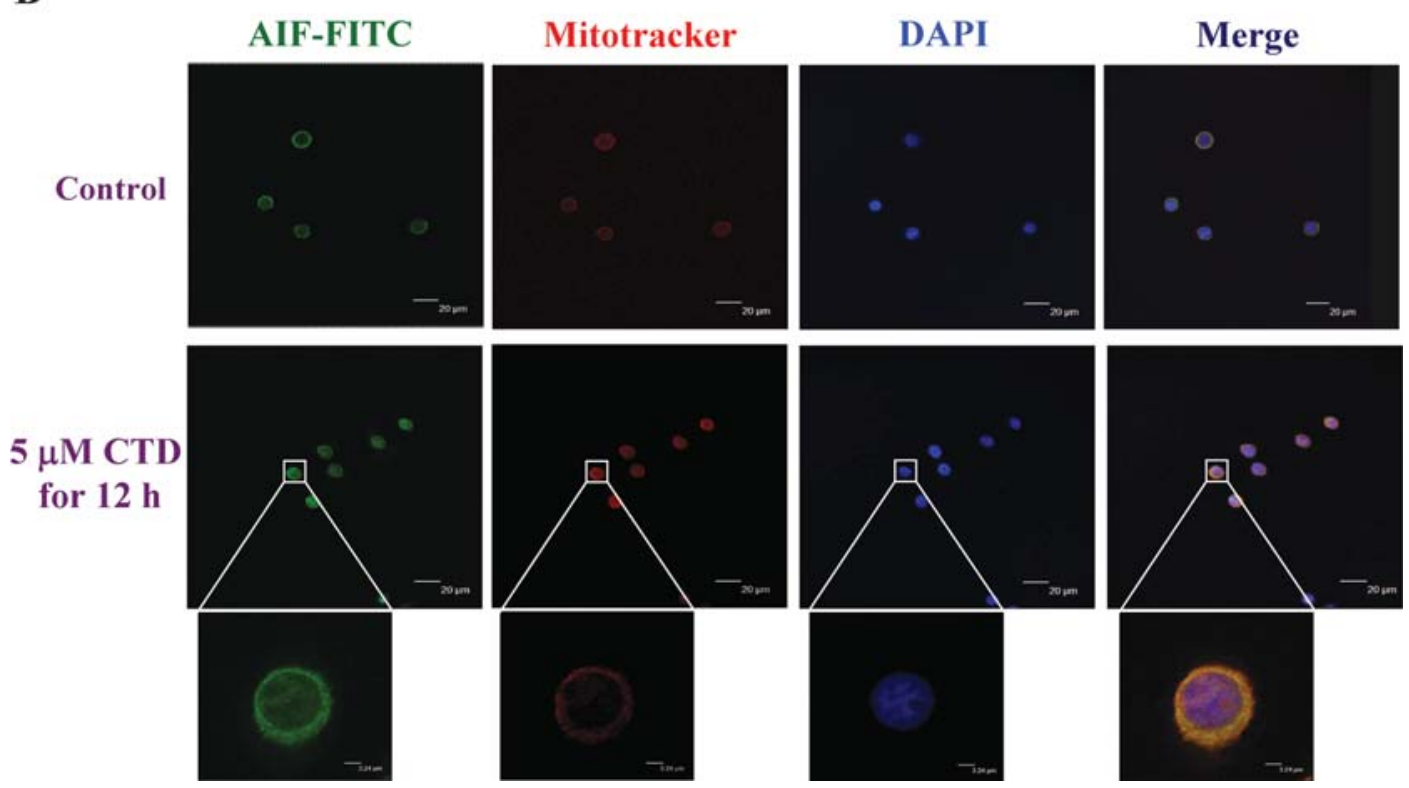

Figure 5. Cantharidin affected Endo G and AIF distribution in TSGH 8301 cells. Cells were incubated with cantharidin at $5 \mu \mathrm{M}$ for $12 \mathrm{~h}$ and then fixed and stained with primary antibodies to Endo G (A) and AIF (B) before FITC-labeled secondary antibodies were used (green fluorescence) and the proteins were detected by a confocal laser microscopic system. The nuclei were stained by mitotracker (red fluorescence). Areas of colocalization between AIF and Endo G expressions and cytoplasm and nuclei in the merged panels are yellow. Scale bar, $40 \mu \mathrm{m}$.

cancer TSGH 8301 cells after exposure to different concentrations of cantharidin and results showed that cantharidin induced apoptosis through mitochondriadependent and JNK signal pathways. Therefore, these novel findings offer more information regarding cantharidininduced apoptosis in human bladder cancer cells. Furthermore, it was reported that cantharidin induces selective cytotoxicity in pancreatic cancer cells with less toxicity in normal pancreatic duct cells (26).

In this study, we investigated the antitumor activity of cantharidin on bladder cancer TSGH 8301 cells. Treatment with cantharidin induced substantial growth inhibition in TSGH 8301 cells (Fig. 1). Further investigation was done for the molecular mechanisms associated with the inhibitory role of cantharidin including cell cycle arrest, apoptosis and the role of mitochondria and results showed that: i) Cantharidin treatment resulted in a marked G0/G1 phase cell cycle arrest (Fig. 2). Western blotting showed that cantharidin increased the levels of p53 and p21 but decreased the levels of Cdc25c and cyclin E that may lead to G0/G1 phase arrest (Fig. 6). Cell cycle is controlled by distinct protein kinase complexes such as cyclins that are necessary for cdc/cdk kinase activity (27). Progression through G1 involves the activation of cyclin D/cdk2, 4, 5 and 6; G1/S involves the activation of cyclin $\mathrm{E} / \mathrm{cdk} 2 ; \mathrm{S}$ involves the activation of cyclin $\mathrm{A} / \mathrm{cdk} 2$, $\mathrm{G} 2 / \mathrm{M}$ is regulated by cyclins A and cyclin B/cdk1 $(28,29)$. ii) Similar to previous reports on other cancer cells, we found that cantharidin induced apoptosis and promoted the active form of caspase-8, -3 and caspase-9 (Fig. 6B), however, we showed that cantharidin decreased the levels of $\Delta \Psi_{m}$ which are involved in AIF, Endo G release from mitochondria, that was the novel finding and may suggest that cantharidin induced apoptosis also through caspase-dependent, -independent and mitochondrial-dependent pathways. Western blotting also showed that cantharidin promoted the expression of Bax (pro-apoptotic protein) and decreased the levels of Bcl-2 (anti-apoptotic protein) (Fig. 6B). This is in agreement with other reports indicated that cantharidin 
$\mathbf{A}$

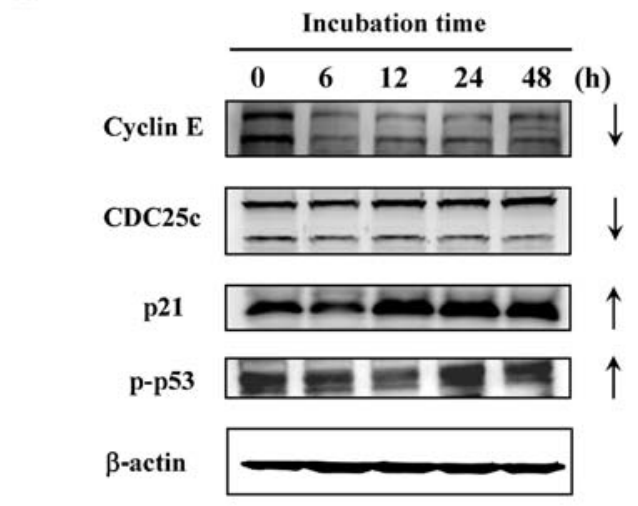

B

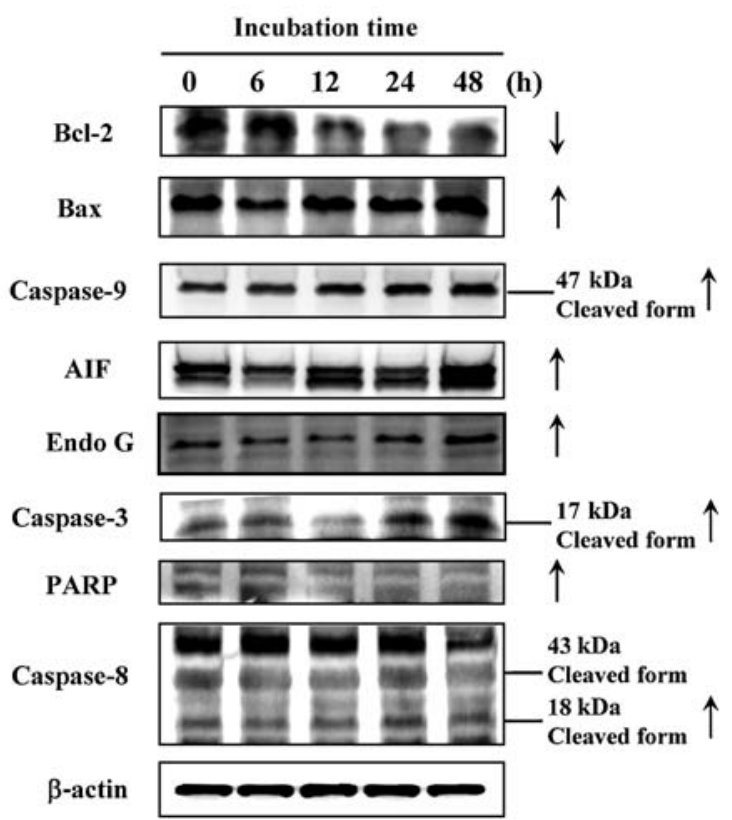

Figure 6. Cantharidin affects the proteins levels of G0/G1 arrest and apoptosis in TSGH 8301 cells. Cells were treated with $5 \mu \mathrm{M}$ of cantharidin for 0,6 , 12,24 and $48 \mathrm{~h}$ then the total proteins were prepared and detected by Western blotting as described in Materials and methods. Respectively, primary antibodies for (A) cyclin E, Cdc25c, p21, p-p53, (B) Bcl-2, Bax, caspase-9, AIF, Endo G, caspase-3, PARP and caspase- 8 were examined by Western blotting. treatment led to dramatically decreased expression of Bcl-2 $(16,30)$. Other reports have shown that some Bcl-2 family members (such as Bax, Bcl-XL, Mcl-1, Bcl-2 and Bid) that are located on the mitochondrial membrane can alter the permeability of the mitochondrial membrane and then led to the activations of caspases followed by apoptotic cell death (9-10,31). iii) Our results also showed that cantharidin promoted the productions of ROS and $\mathrm{Ca}^{2+}$ in TSGH 8301 cells (Fig. 4). This is in agreement with other reports indicating that the cytotoxicity of cantharidin was dependent on the induction of oxidative stress (30) which could induce subsequent apoptosis and cell cycle arrest (32). However, it was reported that cantharidin induced ROS production in human pancreatic cancer PANC-1 and CFPAC- 1 cells in an oxidative stress-independent pathway (26). Furthermore, cantharidin have been showed to induce G2/M phase arrest in human bladder cancer T24 cell line (16), but we found that cantharidin induced $\mathrm{G} 0 / \mathrm{G} 1$ phase arrest in human bladder cancer TSGH 8301 cells (Fig. 2A and B). Apparently, cantharidin-induced cytotoxicity may have cell type specificity. Further investigations are needed.

Furthermore, we tried to investigate whether cantharidininduced cytotoxicity was related to MAPK pathways in bladder cancer TSGG 8301 cells. In the present study, ERK, JNK and p38 were all found to be activated in TSGH 8301 cells when treated with cantharidin. We suggest that the cytotoxicity effect of cantharidin is dependent on the JNK pathway. It has been reported that activation of JNK can increase the expressions of p21 (33), Bad (34), Bak (35) and TNF- $\alpha$ (36) which were found to be escalated when treated with cantharidin, therefore, cantharidin-induced cytotoxicity could be due to the induced JNK activation and the subsequent affect associated genes for further trigger $\mathrm{G} 2 / \mathrm{M}$ phase arrest and apoptosis in TSGH 8301 cells.

In summary, based on these observations, we have obtained convincing evidence that cantharidin efficiently inhibits the growth of human bladder cancer cells through mitochondriadependent signal pathways as shown in Fig. 7. Further investigation on both in vivo and in vitro bladder cancer models is needed.

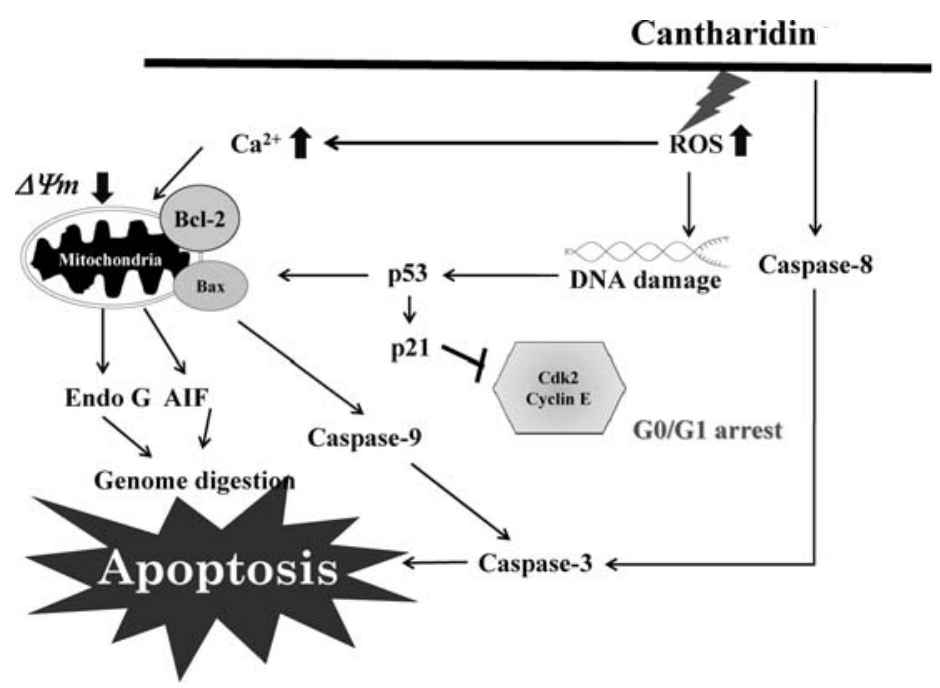

Figure 7. The proposed model of molecular signal pathways from TSGH 9301 cells after exposure to cantharidin. 


\section{References}

1. Orren DK, Petersen LN and Bohr VA: Persistent DNA damage inhibits S-phase and G2 progression, and results in apoptosis. Mol Biol Cell 8: 1129-1142, 1997.

2. Fujimoto K, Hosotani R, Doi R, et al: Induction of cell-cycle arrest and apoptosis by a novel retinobenzoic-acid derivative, TAC-101, in human pancreatic-cancer cells. Int J Cancer 81: 637-644, 1999.

3. Gamet-Payrastre L, Li P, Lumeau S, et al: Sulforaphane, a naturally occurring isothiocyanate, induces cell cycle arrest and apoptosis in HT29 human colon cancer cells. Cancer Res 60: 1426-1433, 2000.

4. Degterev A, Boyce M and Yuan J: A decade of caspases. Oncogene 22: 8543-8567, 2003.

5. Ziegler DS and Kung AL: Therapeutic targeting of apoptosis pathways in cancer. Curr Opin Oncol 20: 97-103, 2008.

6. Klein S, McCormick F and Levitzki A: Killing time for cancer cells. Nat Rev Cancer 5: 573-580, 2005

7. Nakagawa T and Yuan J: Cross-talk between two cysteine protease families. Activation of caspase- 12 by calpain in apoptosis. J Cell Biol 150: 887-894, 2000.

8. Deveraux QL and Reed JC: Iap family proteins-suppressors of apoptosis. Genes Dev 13: 239-252, 1999.

9. Adams JM and Cory S: The Bcl-2 protein family: Arbiters of cell survival. Science 281: 1322-1326, 1998.

10. Antonsson B and Martinou JC: The Bcl-2 protein family. Exp Cell Res 256: 50-57, 2000.

11. Curry SC, Carlton MW and Raschke RA: Prevention of fetal and maternal cyanide toxicity from nitroprusside with coinfusion of sodium thiosulfate in gravid ewes. Anesth Analg 84: 1121-1126, 1997.

12. Honkanen RE: Cantharidin, another natural toxin that inhibits the activity of serine/threonine protein phosphatases types 1 and 2a. FEBS Lett 330: 283-286, 1993.

13. Clarke PR, Hoffmann I, Draetta G and Karsenti E: Dephosphorylation of cdc25-C by a type-2A protein phosphatase: Specific regulation during the cell cycle in Xenopus egg extracts. Mol Biol Cell 4: 397-411, 1993.

14. Chen YN, Chen JC, Yin SC, et al: Effector mechanisms of norcantharidin-induced mitotic arrest and apoptosis in human hepatoma cells. Int J Cancer 100: 158-165, 2002.

15. Kok SH, Cheng SJ, Hong CY, et al: Norcantharidin-induced apoptosis in oral cancer cells is associated with an increase of proapoptotic to antiapoptotic protein ratio. Cancer Lett 217: 43-52, 2005.

16. Huan SK, Lee HH, Liu DZ, Wu CC and Wang CC: Cantharidininduced cytotoxicity and cyclooxygenase 2 expression in human bladder carcinoma cell line. Toxicology 223: 136-143, 2006.

17. Williams LA, Moller W, Merisor E, Kraus W and Rosner H: In vitro anti-proliferation/cytotoxic activity of cantharidin (spanish fly) and related derivatives. West Indian Med J 52: 10-13, 2003.

18. Yi SN, Wass J, Vincent P and Iland H: Inhibitory effect of norcantharidin on K562 human myeloid leukemia cells in vitro. Leuk Res 15: 883-886, 1991.

19. Lin ML, Chung JG, Lu YC, Yang CY and Chen SS: Rhein inhibits invasion and migration of human nasopharyngeal carcinoma cells in vitro by down-regulation of matrix metalloproteinases-9 and vascular endothelial growth factor. Oral Oncol 45: 531-537, 2009.
20. Chiu TH, Lai WW, Hsia TC, et al: Aloe-emodin induces cell death through $\mathrm{S}$-phase arrest and caspase-dependent pathways in human tongue squamous cancer SCC-4 cells. Anticancer Res 29: 4503-4511, 2009

21. Lin ML, Lu YC, Chung JG, et al: Aloe-emodin induces apoptosis of human nasopharyngeal carcinoma cells via caspase-8-mediated activation of the mitochondrial death pathway. Cancer Lett 291: 46-58, 2010.

22. Wu PP, Kuo SC, Huang WW, et al: (-)-epigallocatechin gallate induced apoptosis in human adrenal cancer NCI-H295 cells through caspase-dependent and caspase-independent pathway. Anticancer Res 29: 1435-1442, 2009.

23. Hsu SC, Yang JS, Kuo CL, et al: Novel quinolone CHM-1 induces apoptosis and inhibits metastasis in a human osterogenic sarcoma cell line. J Orthop Res 27: 1637-1644, 2009.

24. Chien SY, Wu YC, Chung JG, et al: Quercetin-induced apoptosis acts through mitochondrial- and caspase-3-dependent pathways in human breast cancer MDA-MB-231 cells. Hum Exp Toxicol 28: 493-503, 2009.

25. Efferth T, Li PC, Konkimalla VS and Kaina B: From traditional chinese medicine to rational cancer therapy. Trends Mol Med 13: 353-361, 2007.

26. Li W, Xie L, Chen Z, et al: Cantharidin, a potent and selective PP2A inhibitor, induces an oxidative stress-independent growth inhibition of pancreatic cancer cells through G2/M cell-cycle arrest and apoptosis. Cancer Sci (In press).

27. Hartwell LH and Weinert TA: Checkpoints: Controls that ensure the order of cell cycle events. Science 246: 629-634, 1989.

28. Malumbres $M$ and Barbacid M: To cycle or not to cycle: A critical decision in cancer. Nat Rev Cancer 1: 222-231, 2001.

29. Jackman M, Lindon C, Nigg EA and Pines J: Active cyclin B1Cdk1 first appears on centrosomes in prophase. Nat Cell Biol 5: 143-148, 2003.

30. Rauh R, Kahl S, Boechzelt H, Bauer R, Kaina B and Efferth T: Molecular biology of cantharidin in cancer cells. Chin Med 2: 8, 2007.

31. Salvesen GS and Dixit VM: Caspases: Intracellular signaling by proteolysis. Cell 91: 443-446, 1997.

32. Ozben T: Oxidative stress and apoptosis: Impact on cancer therapy. J Pharm Sci 96: 2181-2196, 2007.

33. Xiao L, Eto M and Kazanietz MG: ROCK mediates phorbol ester-induced apoptosis in prostate cancer cells via p21Cip1 upregulation and JNK. J Biol Chem 284: 29365-29375, 2009.

34. Lin KL, Su JC, Chien CM, et al: Naphtho[1,2-b]furan-4,5-dione induces apoptosis and S-phase arrest of MDA-MB-231 cells through JNK and ERK signaling activation. Toxicol In Vitro 24: $61-70,2010$.

35. Choi YJ, Kim SY, Oh JM and Juhnn YS: Stimulatory heterotrimeric $G$ protein augments gamma ray-induced apoptosis by up-regulation of Bak expression via CREB and AP-1 in HL299 human lung cancer cells. Exp Mol Med 41: 592-600, 2009.

36. An L, Dong GQ, Gao Q, et al: Effects of UVA on TNF-alpha, IL-1beta, and IL-10 expression levels in human keratinocytes and intervention studies with an antioxidant and a JNK inhibitor. Photodermatol Photoimmunol Photomed 26: 28-35, 2010. 